\title{
Optimization Protocol and Bioactivity Assessment for the Microwave-assisted Extraction of Flavonoids from Eucommia ulmoides Oliver Seed Meal Using Response Surface Methodology
}

\author{
Hui Ouyang, ${ }^{\mathrm{a}, \mathrm{b}, \mathrm{c}, *}$ Songlin Li, ${ }^{\mathrm{c}}$ Wanxi Peng, ${ }^{\mathrm{d}}$ Zhuping Xiao, ${ }^{\mathrm{a}, \mathrm{b}}$ and Yongkang Zhang ${ }^{\mathrm{b}}$
}

\begin{abstract}
Response surface methodology was utilized to optimize the microwaveassisted extraction of flavonoids from Eucommia ulmoides Oliver seed meal. In addition, the optimal processing conditions for the extraction of $E$. ulmoides seed meal flavonoids were as follows: a processing time of 30 min, a liquid to solid ratio of 54 to $1(\mathrm{~mL} / \mathrm{g})$, an ethanol concentration of $77 \%$, and a temperature of $69{ }^{\circ} \mathrm{C}$. The total flavonoids extraction percentage was $0.6611 \%$. Moreover, the total flavonoids extracted from E. ulmoides seed meal were good for scavenging diphenyl picryl hydrazinyl. The E. ulmoides seed meal total flavonoids exhibited an obvious dose-dependent inhibitory effect on a-glucosidase in the concentration range of 0.05 to $1.0 \mathrm{mg} \cdot \mathrm{mL}^{-1}$. The IC50 value of the $E$. ulmoides seed meal flavonoids was slightly lower than the IC50 value of acarbose. According to the results of the xanthine oxidase inhibitory activity test, the IC50 value of the E. ulmoides seed meal flavonoids was higher than the IC50 value of allopurinol.
\end{abstract}

Keywords: Eucommia ulmoides Oliver; Seed meal; Total flavonoids; Optimization; Response surface methodology; Box-Behnken rotatable design; DPPH scavenging activity; $\alpha$-Glucosidase inhibitory activity; XO Inhibitory activity

Contact information: a: Hunan Engineering Laboratory for Analyse and Drugs Development of Ethnomedicine in Wuling Mountains, and College of Chemistry and Chemical Engineering, Jishou University, Jishou 416000 PR China; b: Hunan Provincial Key Laboratory of Investigation and HighValue Utilization on Edible and Medicinal Resources, Jishou University, Jishou, Hunan 416000 China; c: Research Center of Functional Dairy Products for Children's Height Development, Jishou University, Jishou, Hunan 416000 PR China; d: Henan Province Engineering Research Center for Biomass ValueAdded Products, School of Forestry, Henan Agricultural University, Zhengzhou 450002 PR China;

*Corresponding authors: oyhmail@163.com (H. Ouyang)

\section{INTRODUCTION}

Eucommia ulmoides Oliver, known as the Chinese rubber tree (Dù-zhòng) in China, or Tuchong in Japan (Anderson 1982; Wang et al. 2003; Ji and Su 2006), is used extensively as a commercial plant in China (Yao et al. 2012; Pan et al. 2014; Niu et al. 2016). In addition to its leaves and bark, E. ulmoides seeds are a major product of the plant. Because the seeds are rich in linolenic acids and linoleic acid oil, the seed oil has a high antioxidant capacity and biological activation, which can be used for the treatment of hypertension, rheumatoid arthritis, lumbago (Zhang et al. 2010; Wang et al. 2012). As such, it is used as a nutritious plant oil for functional foods (Zhu et al. 2020). The seed meal is a by-product from the production of seed oil, with E. ulmoides seed as the raw material. In a seed oil processing plant, the E. ulmoides seed meal (EUOSM) is often neglected and usually discarded as a waste product or fertilizer. 
Correlation studies between the bioactivities and the total flavonoids content of various plant seeds have been undertaken (Farombi et al. 2002; Arimboor and Arumughan 2012; Orak et al. 2012; Yan et al. 2011; Xu et al. 2015; Ayoub et al. 2016). However, the flavonoids in defatted E. ulmoides seed meal, as well as its related activities, have few published studies.

Microwave assisted extraction (MAE) is a new green technology. Microwaves can quickly transfer energy, improve the extraction yield, and reduce the extraction time and solvent consumption (Eskilsson and Bjorklund 2000; Guo et al. 2001).

In the present study, E. ulmoides seed meal (EUOSM) was used as the research object. Then, through microwave-assisted extraction, the flavonoids were extracted from the seed meal (Guo et al. 2001; Fu et al. 2020). Through the preliminary screening using the single factor method, the significant factors that affect the yield of the EUOSM total flavonoids content will be further optimized via the response surface methodology (RSM) to obtain the optimal extraction conditions for flavonoids extraction from EUOSM, using a four factors RSM Box-Behnken design (BBD). Moreover, diphenyl picryl hydrazinyl (DPPH) scavenging, $\alpha$-glucosidase inhibition, and xanthine oxidase (XO) inhibition were used to investigate the activity of the flavonoids from EUOSM.

\section{EXPERIMENTAL}

\section{Materials}

Eucommia ulmoides Oliver seeds were collected from the Cili, Zhangjiajie, and Hunan provinces in China. The seeds were pressed using supercritical fluid extraction technology. The seed meal was defatted with hexane (a 1 to 10 ratio, w/v) via extraction in a Soxhlet apparatus for $24 \mathrm{~h}$. After air-drying to remove the residual solvent, the defatted product was obtained, which was kept in sealed plastic bags at a temperature of $-4{ }^{\circ} \mathrm{C}$ prior to extraction.

\section{Microwave-assisted Extraction}

A multifunctional pulverizer was used to pulverize the dried EUOSM. It was then passed through a 60-mesh sieve. The sieved product was used to conduct experiments according to the four factors, i.e., microwave time (min), ethanol concentration (\%), extraction temperature $\left({ }^{\circ} \mathrm{C}\right)$, and liquid to solid ratio $(\mathrm{mL} / \mathrm{g})$. In addition, the total flavonoids content was determined and calculated after extraction.

\section{Determination of the Total Flavonoids Content}

The total flavonoids content, expressed as rutin equivalents (RE), was determined by a colorimetric method using aluminum nitrate, as described by Moreno et al. (2000), with slight modifications. First, $1.44 \mathrm{~mL}$ of the sample solution was diluted with $0.64 \mathrm{~mL}$ of a $70 \%$ ethanol solution. Then, $0.16 \mathrm{~mL}$ of a $5 \mathrm{~g} / 100 \mathrm{~g} \mathrm{NaNO} 2$ solution was added to the mixture, and after $6 \mathrm{~min}, 0.16 \mathrm{~mL}$ of a $10 \mathrm{~g} / 100 \mathrm{~g} \mathrm{AL}\left(\mathrm{NO}_{3}\right)_{3}$ solution was added. The mixture was allowed to stand for $6 \mathrm{~min}$, and then $1.6 \mathrm{~mL}$ of a $4 \mathrm{~g} / 100 \mathrm{~g} \mathrm{NaOH}$ in an aqueous solution was added. The solution was mixed well, and immediately afterwards the absorbance was measured against a blank at $510 \mathrm{~nm}$ using a UV-VIS spectrophotometer after standing for $12 \mathrm{~min}$. The results were expressed as $\mathrm{mg}$ of rutin equivalents. 


\section{Diphenyl Picryl Hydrazinyl (DPPH) Radical Scavenging Assay}

The DPPH free radical scavenging capacity was calculated according to Zhu et al. (2020), with slight modifications. A total of $2 \mathrm{~mL}$ of freshly prepared $0.246 \mathrm{mg} / \mathrm{mL} \mathrm{DPPH}$ solution (the blank solution was equivalent ethanol) was mixed with an appropriate amount of the determinant solution in a water bath at a temperature of $25^{\circ} \mathrm{C}$ in a dark place. After $30 \mathrm{~min}$, the absorbance was measured at least three times per blend via a UV-VIS spectrophotometer at $510 \mathrm{~nm}$.

\section{a-Glucosidase Inhibitory Activity Assay}

The $\alpha$-glucosidase inhibition activity of the EUOSM flavonoids were measured according to Asghari et al. (2015), with slight modifications. First, $160 \mu \mathrm{L}$ of phosphate buffer (a pH of 6.9), $20 \mu \mathrm{L}$ of $\alpha$-glucosidase, and $20 \mu \mathrm{L}$ of the sample solution in different concentrations were added into 96-well plate in sequence. Then, the mixture was stored at a temperature of $37{ }^{\circ} \mathrm{C}$ for $15 \mathrm{~min}$, using acarbose as the positive control. Next, $40 \mu \mathrm{L}$ of PNPG (4-nitrophenyl- $\beta$-D-glucopyranoside) was added and incubating at a temperature of $37{ }^{\circ} \mathrm{C}$ for $30 \mathrm{~min}$. The OD value was measured at $405 \mathrm{~nm}$ using a microplate reader (SPECTRA Max-Plus 384, Molecular Devices, Sunnyvale, CA, USA).

\section{Xanthine Oxidase (XO) Inhibitory Activity Assay}

The XO inhibitory activity of the EUOSM flavonoids were measured according to Nguyen et al. (2004) by using 96-well plates. The OD value was measured at $290 \mathrm{~nm}$ using a microplate reader.

\section{Statistical Analysis}

Statistical analysis was carried out using SPSS software (Version 17.0, SPSS Inc., Chicago, IL). Origin software (Version 8.5, OriginLab Co., Northampton, MA, USA) was used for data interpolation, fitting, and curve plotting. The design of the experiments, analysis of the results, and prediction of the responses were carried out using DesignExpert software (Version 11, Stat-Ease, Inc., Minneapolis, MN, USA).

\section{RESULTS AND DISCUSSION}

\section{Effects of the Single Factor Extraction Conditions}

Microwave irradiation time

The introduction of a microwave-assisted method for the extraction of flavonoids can effectively reduce the extraction time and energy consumption; as such, it is an efficient method (Jing et al. 2019; Memarzadeh et al. 2020). Figure 1A shows that when the microwave irradiation time ranged from 15 to $35 \mathrm{~min}$, the total flavonoids yield markedly increased and reached its maximum value after $30 \mathrm{~min}$. When the extraction time was greater than $30 \mathrm{~min}$, the flavonoids extraction rate began to significantly decrease. In contrast, when the microwave irradiation time continued longer than $35 \mathrm{~min}$, the flavonoids extraction rate showed a slight decrease, which may be related to the loss of flavonoids components. According to the results shown in Fig. 1A, an appropriate extraction time for the extraction of flavonoids should be limited to within 25 to $35 \mathrm{~min}$. 

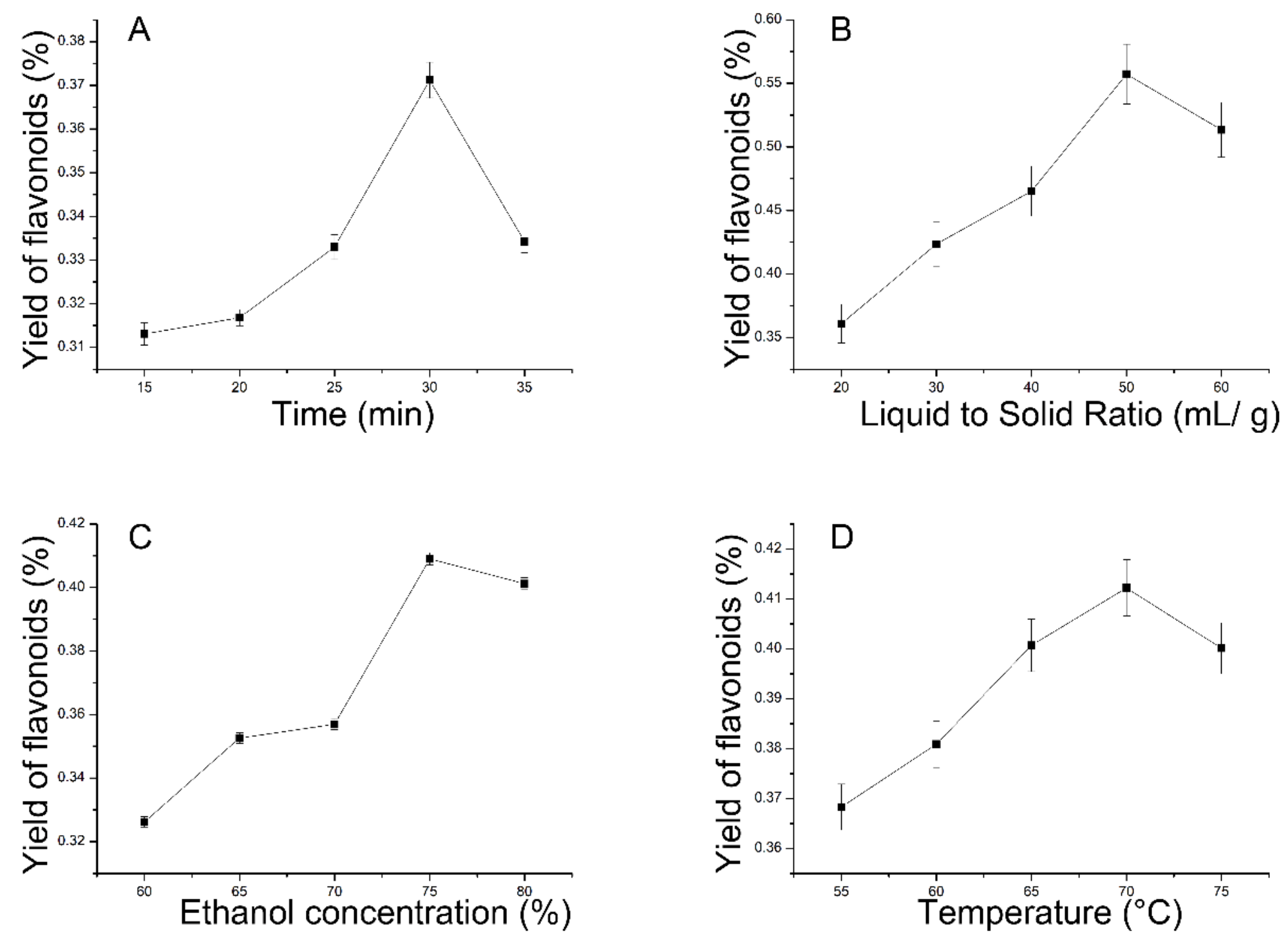

Fig. 1. Effects of the different parameters on the flavonoids yield: A) Time; B) Liquid to solid ratio; C) Ethanol concentration; and D) Temperature 


\section{Liquid to solid ratio}

As shown in Fig. 1B, the flavonoids extraction rate significantly increased as the liquid to solid ratio was increased from $20: 1(\mathrm{~mL} / \mathrm{g})$ to $50: 1(\mathrm{~mL} / \mathrm{g})$ and reached the maximum extraction rate at a liquid to solid ratio of $50: 1(\mathrm{~mL} / \mathrm{g})$. Moreover, the results shown in Fig. 1B indicate that the optimal liquid to solid ratio for flavonoids extraction may appear in the ratio range of 40:1 through 60:1. Additional information is needed for further optimization.

\section{Ethanol concentration}

The changing trend of the total flavonoids yield with relation to the ethanol concentration is shown in Fig. 1C; the total flavonoids yield increased as the ethanol concentration increased. The total flavonoids yield was the highest when the ethanol concentration reached $75 \%$. When the ethanol concentration ranged between $75 \%$ and $80 \%$, the total flavonoids yield showed a downward trend. Therefore, it was advisable to keep the ethanol concentration between $70 \%$ to $80 \%$.

\section{Temperature}

Figure 1D shows that the highest flavonoids extraction occurred when the temperature was increased to $70{ }^{\circ} \mathrm{C}$. The flavonoids extraction extent decreased when the temperature ranged from 70 to $75{ }^{\circ} \mathrm{C}$. Considering that a high temperature might affect the structure and biological activity of the flavonoids, an excessively high temperature would reduce the extent of flavonoids extraction. Therefore, it was advisable to keep the temperature between $65^{\circ} \mathrm{C}$ and $75^{\circ} \mathrm{C}$.

\section{Optimal Extraction Conditions via Box-Behnken Design (BBD)}

Based on single factor screening, the effects of the time, liquid to solid ratio, ethanol concentration, and temperature on the flavonoids yield were optimized via the BBD method. The actual value and the predicted value of the total flavonoids yield, the analysis of variance of the model, and the reliability test of the regression equation are listed in Tables 1 and 2 .

The results of the ANOVA are shown in Table 2, and the multivariate regressionfitting model was used to obtain the quadratic regression equation of the total flavonoids yield for four independent variables, as shown in Eq. 1,

$$
\begin{aligned}
& \mathrm{Y}=-8.76506+0.11409 \cdot \mathrm{A}+0.041514 \cdot \mathrm{B}+0.057058 \cdot \mathrm{C}+0.12646 \cdot \mathrm{D}+4.50000 \mathrm{E}- \\
& 005 \cdot \mathrm{A} \cdot \mathrm{B}-3.43000 \mathrm{E}-004 \cdot \mathrm{A} \cdot \mathrm{C}-7.09000 \mathrm{E}-004 \cdot \mathrm{A} \cdot \mathrm{D}-2.15000 \mathrm{E}- \\
& 005 \cdot \mathrm{B} \cdot \mathrm{C}+3.00000 \mathrm{E}-005 \cdot \mathrm{B} \cdot \mathrm{D}-2.83000 \mathrm{E}-004 \cdot \mathrm{C} \cdot \mathrm{D}-6.81933 \mathrm{E}-004 \cdot \mathrm{A}^{2}- \\
& 3.97358 \mathrm{E}-004 \cdot \mathrm{B}^{2}-1.68433 \mathrm{E}-004 \cdot \mathrm{C}^{2}-6.13933 \mathrm{E}-004 \cdot \mathrm{D}^{2}
\end{aligned}
$$

where $\mathrm{A}$ is the extraction time ( $\mathrm{min}), \mathrm{B}$ is the liquid to solid ratio $(\mathrm{mL} / \mathrm{g}), \mathrm{C}$ is ethanol concentration (\%), D is temperature $\left({ }^{\circ} \mathrm{C}\right)$, and $\mathrm{Y}$ is the total flavonoids yield (\%).

The ANOVA analysis of the total flavonoids yield is presented in Table 2.

The linear coefficients (B, C, and D) were significant, which indicated that the liquid to solid ratio, ethanol concentration, and temperature greatly influenced the total flavonoids yield.

The interaction terms ( $A C$ and $\mathrm{AD})$ and the quadratic terms $\left(\mathrm{A}^{2}, \mathrm{~B}^{2}\right.$, and $\left.\mathrm{D}^{2}\right)$ were significant (a $p$-value less than 0.001). The obtained F-value (231.1873) and the corresponding $p$-value (lower than 0.0001 ) implied that the model was highly significant. The lack of fit F-value (1.74) implied the lack of fit was not significant relative to the pure 
error. There was a $31.19 \%$ chance that a lack of fit F-value this large could occur due to noise.

The $\mathrm{R}^{2}$ equaled 0.9957 , which indicated that the model could explain $99.57 \%$ variation of the total flavonoids yield. The regression equation was significant, and the relationship between each factor and response value could be accurately described. Therefore, the equation could determine the optimal flavonoids extraction process parameters.

Table 1. Results of the Response Surface Analysis

\begin{tabular}{|c|c|c|c|c|c|c|}
\hline \multirow{3}{*}{ Run } & \multicolumn{4}{|c|}{ Factor } & & \\
\hline & A & B & C & $\mathrm{D}$ & \multicolumn{2}{|c|}{ Flavonoids Yield (\%) } \\
\hline & $\begin{array}{l}\text { Time } \\
(\min )\end{array}$ & $\begin{array}{l}\text { Liquid to } \\
\text { Solid Ratio } \\
(\mathrm{mL} / \mathrm{g})\end{array}$ & $\begin{array}{c}\text { Ethanol } \\
\text { Concentration } \\
(\%)\end{array}$ & $\begin{array}{c}\text { Temperature } \\
\left({ }^{\circ} \mathrm{C}\right)\end{array}$ & Experimental & Predicted \\
\hline 1 & 30 & 40 & 75 & 75 & 0.5558 & 0.5524 \\
\hline 2 & 30 & 60 & 80 & 70 & 0.6380 & 0.6417 \\
\hline 3 & 30 & 40 & 70 & 70 & 0.5636 & 0.5633 \\
\hline 4 & 25 & 50 & 75 & 65 & 0.5968 & 0.5995 \\
\hline 5 & 30 & 50 & 70 & 65 & 0.6201 & 0.6202 \\
\hline 6 & 30 & 40 & 80 & 70 & 0.5675 & 0.5716 \\
\hline 7 & 30 & 50 & 75 & 70 & 0.6437 & 0.6475 \\
\hline 8 & 25 & 40 & 75 & 70 & 0.5562 & 0.5565 \\
\hline 9 & 35 & 60 & 75 & 70 & 0.6284 & 0.6295 \\
\hline 10 & 30 & 50 & 70 & 75 & 0.6272 & 0.6295 \\
\hline 11 & 30 & 60 & 70 & 70 & 0.6384 & 0.6377 \\
\hline 12 & 30 & 50 & 80 & 65 & 0.6415 & 0.6406 \\
\hline 13 & 30 & 50 & 75 & 70 & 0.6462 & 0.6475 \\
\hline 14 & 35 & 50 & 70 & 70 & 0.6316 & 0.6321 \\
\hline 15 & 30 & 50 & 75 & 70 & 0.6478 & 0.6475 \\
\hline 16 & 25 & 60 & 75 & 70 & 0.6247 & 0.6243 \\
\hline 17 & 25 & 50 & 75 & 75 & 0.6269 & 0.6301 \\
\hline 18 & 35 & 40 & 75 & 70 & 0.5509 & 0.5527 \\
\hline 19 & 30 & 50 & 80 & 75 & 0.6203 & 0.6216 \\
\hline 20 & 30 & 60 & 75 & 75 & 0.6301 & 0.6277 \\
\hline 21 & 30 & 40 & 75 & 65 & 0.5611 & 0.5602 \\
\hline 22 & 30 & 50 & 75 & 70 & 0.6499 & 0.6475 \\
\hline 23 & 25 & 50 & 70 & 70 & 0.6147 & 0.6143 \\
\hline 24 & 30 & 60 & 75 & 65 & 0.6294 & 0.6295 \\
\hline 25 & 35 & 50 & 75 & 65 & 0.6354 & 0.6356 \\
\hline 26 & 25 & 50 & 80 & 70 & 0.6414 & 0.6376 \\
\hline 27 & 30 & 50 & 75 & 70 & 0.6488 & 0.6475 \\
\hline 28 & 35 & 50 & 80 & 70 & 0.624 & 0.6211 \\
\hline 29 & 35 & 50 & 75 & 75 & 0.5946 & 0.5953 \\
\hline
\end{tabular}


Table 2. Analysis of Variance for the Response Surface Quadratic Model

\begin{tabular}{|c|c|c|c|c|c|}
\hline Source & Sum of Squares & $d f$ & Mean Square & F-value & $p$-value \\
\hline Model & 0.029018 & 14 & 0.002073 & 231.1873 & $<0.0001$ \\
\hline A & $1.47 \mathrm{E}-06$ & 1 & 1.47E-06 & 0.163962 & 0.6917 \\
\hline$B$ & 0.015689 & 1 & 0.015689 & 1749.939 & $<0.0001$ \\
\hline $\mathrm{C}$ & 0.000115 & 1 & 0.000115 & 12.79356 & 0.0030 \\
\hline $\mathrm{D}$ & 7.2E-05 & 1 & $7.2 \mathrm{E}-05$ & 8.03412 & 0.0132 \\
\hline$A B$ & 2.03E-05 & 1 & 2.03E-05 & 2.258655 & 0.1551 \\
\hline$A C$ & 0.000294 & 1 & 0.000294 & 32.80599 & $<0.0001$ \\
\hline$A D$ & 0.001257 & 1 & 0.001257 & 140.1707 & $<0.0001$ \\
\hline $\mathrm{BC}$ & 4.62E-06 & 1 & 4.62E-06 & 0.515587 & 0.4845 \\
\hline $\mathrm{BD}$ & 9E-06 & 1 & 9E-06 & 1.003847 & 0.3334 \\
\hline$C D$ & 0.0002 & 1 & 0.0002 & 22.33252 & 0.0003 \\
\hline$A^{2}$ & 0.001885 & 1 & 0.001885 & 210.2802 & $<0.0001$ \\
\hline $\mathrm{B}^{2}$ & 0.010242 & 1 & 0.010242 & 1142.35 & $<0.0001$ \\
\hline $\mathrm{C}^{2}$ & 0.000115 & 1 & 0.000115 & 12.82834 & 0.0030 \\
\hline $\mathrm{D}^{2}$ & 0.001528 & 1 & 0.001528 & 170.4342 & $<0.0001$ \\
\hline Residual & 0.000126 & 14 & 8.97E-06 & & \\
\hline Lack of fit & 0.000102 & 10 & 1.02E-05 & 1.743028 & 0.3119 \\
\hline Pure error & 2.34E-05 & 4 & $5.86 \mathrm{E}-06$ & & \\
\hline $\begin{array}{c}\text { Corrected } \\
\text { total }\end{array}$ & 0.029143 & 28 & & & \\
\hline $\mathrm{R}^{2}$ & 0.9957 & & & & \\
\hline $\mathrm{R}^{2} \mathrm{adj}$ & 0.9914 & & & & \\
\hline C.V.\% & 0.49 & & & & \\
\hline
\end{tabular}

\section{Plotted Results of the Response Surface Analysis}

From the regression equation, the response surface and contour maps of the ratio of liquid to time, the liquid to solid ratio, the ethanol concentration, and the temperature affecting the total flavonoids yield were obtained, as shown in Figs. 2A through 2F.

Figure $2 \mathrm{~A}$ shows that the effect of the time and liquid to solid ratio on the total flavonoids yield was parabolic. The total flavonoids yield first increased and then decreased as the time and liquid to solid ratio increased. According to Fig. 2B, the total flavonoids yield first increased and then tended to plateau as the time and ethanol concentration increased. As shown in Fig. $2 \mathrm{C}$, as the time and temperature increased, the total flavonoids yield gradually increased and then tended to plateau. Figure 2D shows that the effect of the liquid to solid ratio and ethanol concentration on the total flavonoids yield was parabolic. The total flavonoids yield first increased and then decreased as the time and liquid to solid ratio increased. Figure $2 \mathrm{E}$ shows that as the liquid to solid ratio and temperature increased, the total flavonoids yield first increased and then decreased. From plots of the response surface and contours, the total flavonoids yield did not increase after a certain value when the ethanol concentration and temperature increased, as shown in Fig. $2 \mathrm{~F}$.

In this study, within the limits of the factors affecting the total flavonoids yield, the optimum conditions were predicted as follows: a time of $30.1 \mathrm{~min}$, a liquid to solid ratio of 54.5 to $1(\mathrm{~mL} / \mathrm{g})$, an ethanol concentration of $77.2 \%$, and a temperature of $69.2{ }^{\circ} \mathrm{C}$, with a 
total flavonoids yield of $0.656 \%$. Considering the actual laboratory extraction conditions, the optimal extraction conditions for flavonoids extraction were adjusted to a time of 30 min, a liquid to solid ratio of 54 to $1(\mathrm{~mL} / \mathrm{g})$, an ethanol concentration of $77 \%$, and a temperature (D) of $69{ }^{\circ} \mathrm{C}$. To verify and confirm the optimal extraction conditions, the flavonoids extraction process was performed in triplicate, and the average flavonoids extraction rate was calculated as $0.661 \%$, which was highly similar to the predicted value $(0.656 \%)$. This showed that the optimized process was reliable and reproducible in terms of flavonoids extraction.
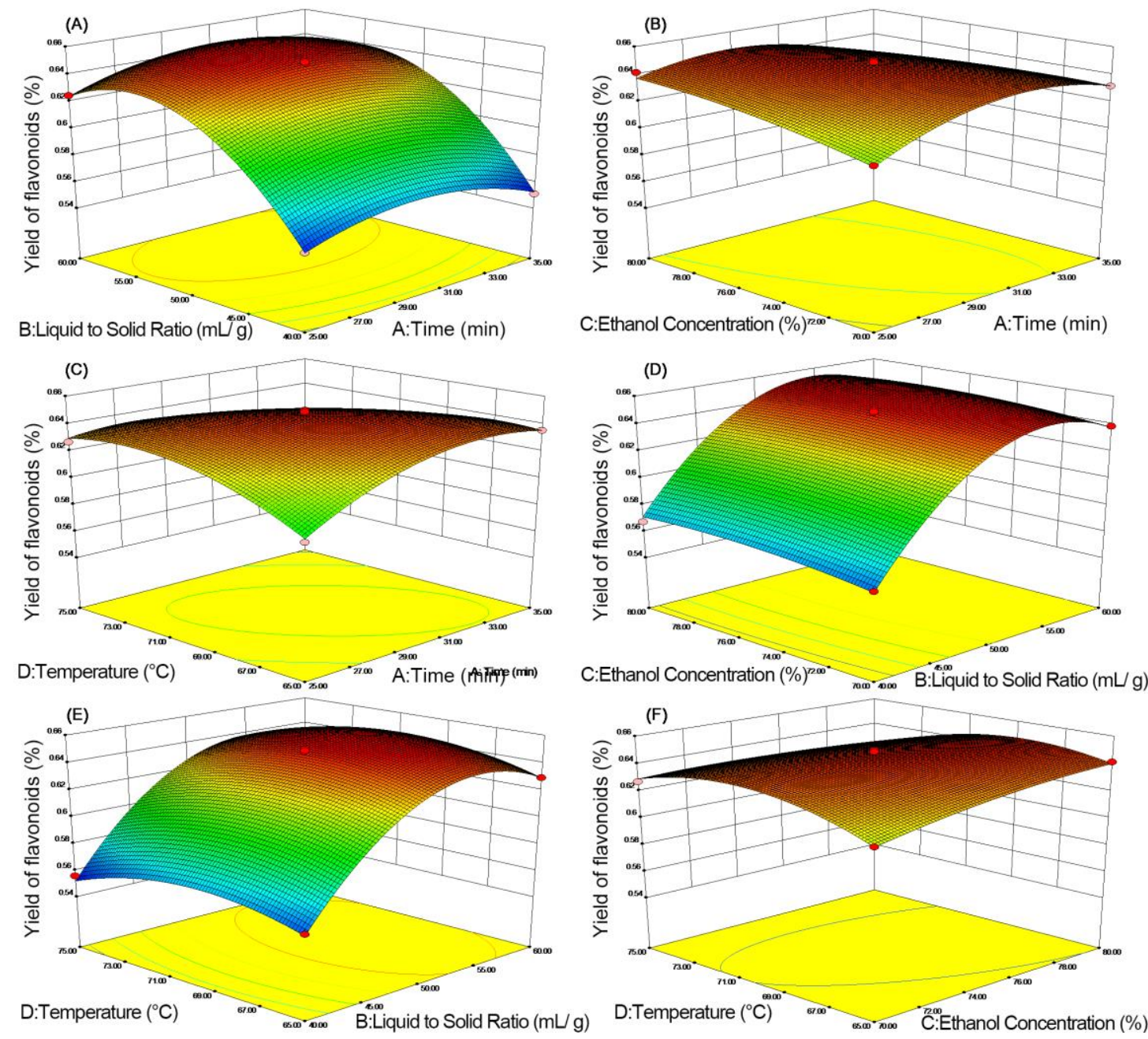

Fig. 2. Response surface (3D) showing the optimization of the flavonoid yield via the Box-Behnken design (BBD) method

\section{Diphenyl Picryl Hydrazinyl (DPPH) Radical Scavenging Analysis}

Diphenyl picryl hydrazinyl (DPPH) free radicals, as one of the most harmful reactive oxygen species (ROS), is usually associated with oxidative injury, resulting in tissue damage and even cell death. As shown in Fig. 3, E. ulmoides seed flavonoids and Vitamin C (VC) exhibited an obvious dose-dependent inhibitory effect on DPPH free radicals. The DPPH scavenging ability of E. ulmoides seed flavonoids was lower than that of $\mathrm{VC}$, ranging from $0.005 \mathrm{mg} / \mathrm{mL}$ to $0.01 \mathrm{mg} / \mathrm{mL}$. The results showed that the flavonoids extracted from $E$. ulmoides seed meal were good for scavenging DPPH. 

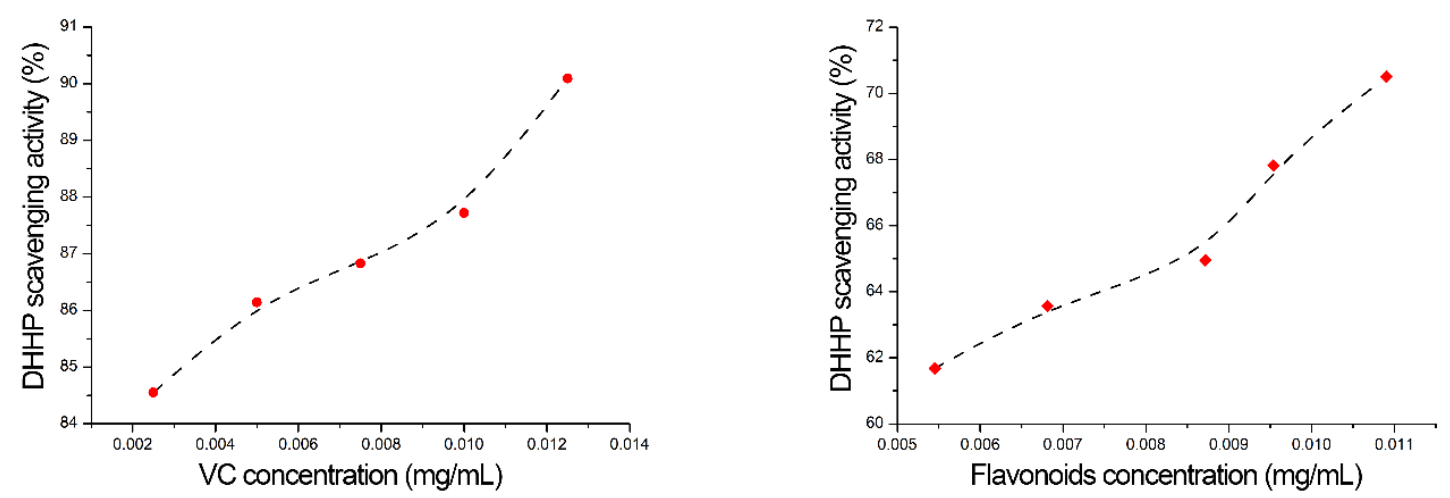

Fig. 3. Linear regression plots for the DPPH radical scavenging (Flavonoids and VC)

\section{a-Glucosidase Inhibitory Activity Analysis}

Slowing carbohydrate digestion and glucose absorption by inhibiting $\alpha$-glucosidase activity has been widely used to control postprandial blood sugar in order to treat diabetes.
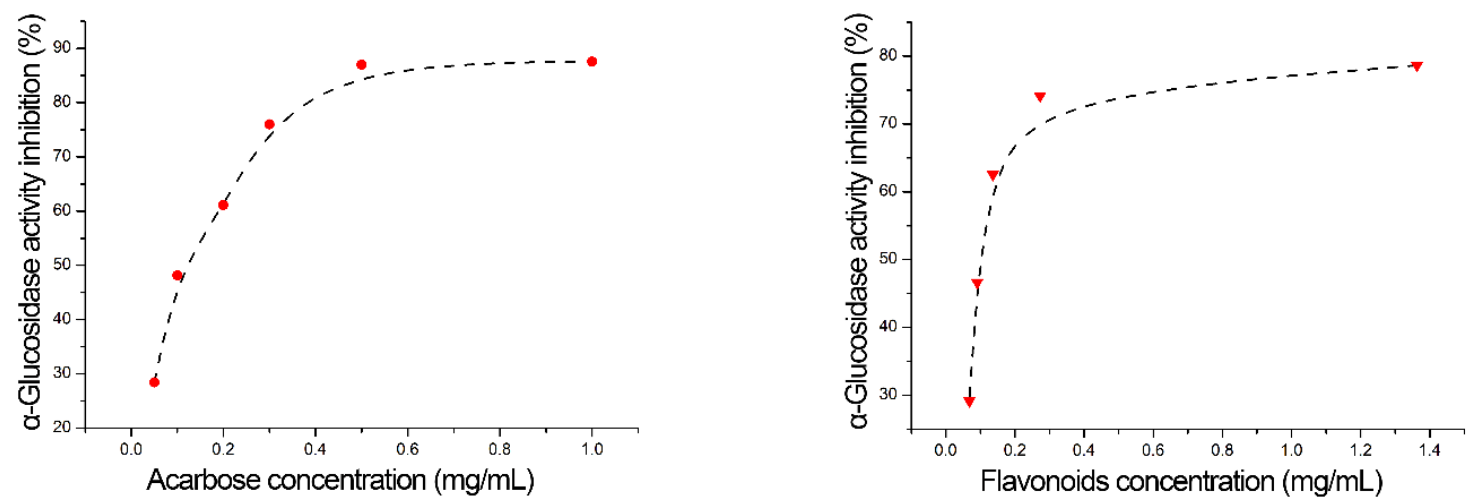

Fig. 4. a-Glucosidase inhibitory activity of flavonoids

As shown in Fig. 4, the EUOSM total flavonoids content and acarbose exhibited an obvious dose-dependent inhibitory effect on $\alpha$-glucosidase in the concentration range of 0.05 to $1.0 \mathrm{mg} \cdot \mathrm{mL}^{-1}$. The IC50 values of the EUOSM total flavonoids content and acarbose were 0.1122 and $0.1134 \mathrm{mg} \cdot \mathrm{mL}^{-1}$, respectively (Table 3 ). The IC50 value of the total EUOSM flavonoids content was slightly smaller than the IC50 value of acarbose.

Table 3. The a-Glucosidase Inhibitory Activity of Flavonoids in Extracts Obtained from E. ulmoides Seed

\begin{tabular}{|c|c|c|c|c|c|c|c|}
\hline Sample & Parameter & Estimate & $\begin{array}{c}\text { Std. } \\
\text { Error }\end{array}$ & $\begin{array}{c}\text { Probit Regressive } \\
\text { Equation }\end{array}$ & $\begin{array}{c}\mathrm{IC}_{50} \\
\left(\mathrm{mg}^{\prime} \mathrm{mL}^{-1}\right)\end{array}$ & $\mathrm{p}$ & Sig. \\
\hline \multirow{2}{*}{ Flavonoids } & Intercept & 1.521 & 0.241 & $\mathrm{Y}=1.521+1.601 \mathrm{lg}$ & 0.1122 & $<0.0001$ & ${ }^{* *}$ \\
\cline { 2 - 6 } & $\mathrm{X}$ & 1.601 & 0.214 & $(\mathrm{X})$ & $<0.0001$ & ${ }^{* *}$ \\
\hline \multirow{2}{*}{ Acarbose } & Intercept & 2.304 & 0.207 & $\mathrm{Y}=2.304+2.437 \mathrm{lg}$ & 0.1134 & $<0.0001$ & ${ }^{* *}$ \\
\cline { 2 - 6 } & $\mathrm{X}$ & 2.437 & 0.247 & $(\mathrm{X})$ & $<0.0001$ & ${ }^{* *}$ \\
\hline
\end{tabular}




\section{Xanthine Oxidase (XO) Inhibitory Activity Analysis}

Figure 5 shows that the total EUOSM flavonoids content had a strong inhibitory effect on xanthine oxidase. The inhibitory activity increased as the flavonoids concentration increased. According to the results of the xanthine oxidase inhibitory activity test, the total EUOSM flavonoids content was positively correlated with the bacteriostasis effect. The IC50 values of the total EUOSM flavonoids content and allopurinol were 21.1 and $8.3 \mu \mathrm{g} \cdot \mathrm{mL}^{-1}$, respectively (Table 4). The IC50 value of the total EUOSM flavonoids content was higher than the IC50 value of allopurinol.
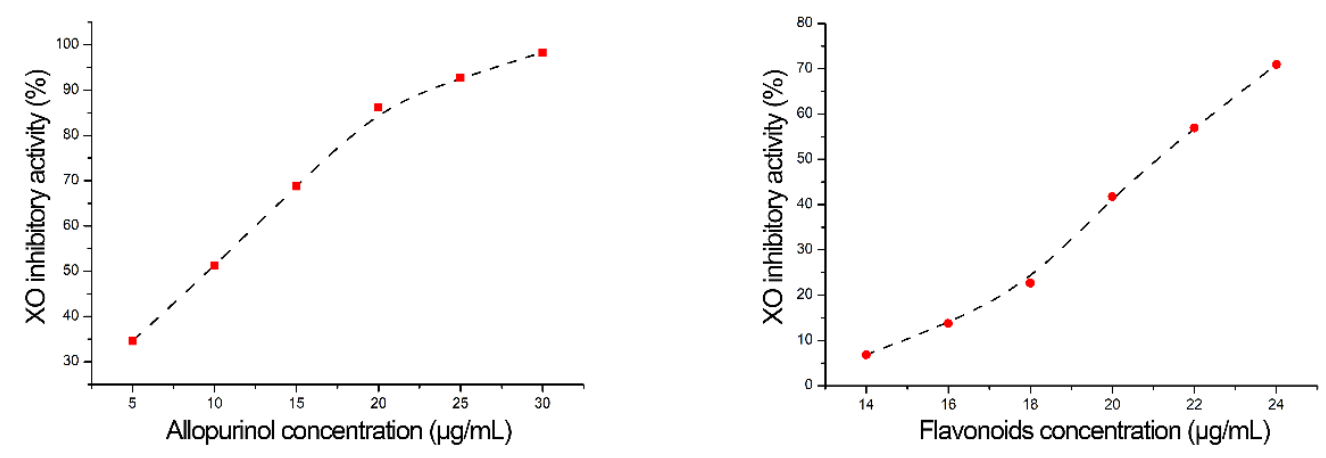

Fig. 5. The XO inhibitory activity of flavonoids

Table 4. Xanthine Oxidase (XO) Inhibitory Activity of Flavonoids in Extracts Obtained from E. ulmoides Seed

\begin{tabular}{|c|c|c|c|c|c|c|c|}
\hline Sample & Parameter & Estimate & $\begin{array}{l}\text { Std. } \\
\text { Error }\end{array}$ & $\begin{array}{c}\text { Probit Regressive } \\
\text { Equation }\end{array}$ & $\begin{array}{c}\mathrm{IC}_{50} \\
\left(\mathrm{mg} \cdot \mathrm{mL}^{-1}\right)\end{array}$ & $p$ & Sig. \\
\hline \multirow{2}{*}{ Flavonoids } & Intercept & -20.539 & 1.483 & \multirow{2}{*}{$\begin{array}{c}Y=-20.539+ \\
15.506 \lg (X)\end{array}$} & \multirow{2}{*}{21.1140} & $<0.0001$ & ** \\
\hline & $\mathrm{X}$ & 15.506 & 1.929 & & & $<0.0001$ & $* *$ \\
\hline \multirow{2}{*}{ Allopurinol } & Intercept & -4.225 & 0.467 & \multirow{2}{*}{$\begin{array}{c}Y=-4.225+ \\
4.608 \lg (X)\end{array}$} & \multirow{2}{*}{8.2581} & $<0.0001$ & $\star \star$ \\
\hline & $\mathrm{X}$ & 4.608 & 0.419 & & & $<0.0001$ & ** \\
\hline
\end{tabular}

\section{CONCLUSIONS}

1. The optimal process for the extraction of EUOSM flavonoids was found to be as follows: a time of $30 \mathrm{~min}$, a liquid to solid ratio of 54 to $1(\mathrm{~mL} / \mathrm{g})$, an ethanol concentration of $77 \%$, and a temperature of $69^{\circ} \mathrm{C}$. The extraction yield of the EUOSM flavonoids was $0.6611 \%$.

2. The EUOSM flavonoids were good for scavenging DPPH. The DPPH scavenging ability of the EUOSM flavonoids was lower than the DPPH scavenging ability of VC at a range of $0.005 \mathrm{mg} / \mathrm{mL}$ to $0.01 \mathrm{mg} / \mathrm{mL}$.

3. The EUOSM flavonoids exhibited an obvious dose-dependent inhibitory effect on $\alpha$ glucosidase at a concentration range from $0.05 \mathrm{mg} \cdot \mathrm{mL}^{-1}$ to $1.0 \mathrm{mg} \cdot \mathrm{mL}^{-1}$. The IC50 value of the total EUOSM flavonoids content was slightly smaller than the IC50 value of acarbose.

4. According to the results of the xanthine oxidase inhibitory activity test, the IC50 value of the total EUOSM flavonoids content was higher than the IC50 value of allopurinol. 


\section{ACKNOWLEDGMENTS}

This work was financially supported by the Science and Technology Innovation Program of the Hunan Province (Project no. 2018NK2042), the Science and Technology Program of the Xiangxi Autonomous Prefecture (Project no. 2019SF2005), the National Natural Science Foundation of China (Project no. 31560192), and the Technology Development Project of Hunan Gaoge Dairy Co., Ltd (Project no. 20431415000005).

\section{REFERENCES CITED}

Anderson, W. R. (1982). "An integrated system of classification of flowering plants," Brittonia 34(2), 268-270. DOI: 10.2307/2806386

Arimboor, R, and Arumughan, C. (2012). "HPLC-DAD-MS/MS profiling of antioxidant flavonoid glycosides in sea buckthorn (Hippophae rhamnoides L.) seeds," International Journal of Food Sciences and Nutrition 63(6), 730-738. DOI: 10.3109/09637486.2011.652075

Asghari, B., Salehi, P., Sonboli, A., and Ebrahimi, S. N. (2015). "Flavonoids from Salvia chloroleuca with $\alpha$-amylsae and $\alpha$-glucosidase inhibitory effect," Iranian Journal of Pharmaceutical Research 14(2), 609-615.

Ayoub, M., Camargo, A. C. d., and Shahidi, F. (2016). "Antioxidants and bioactivities of free, esterified and insoluble-bound phenolics from berry seed meals," Food Chemistry 197(Part A), 221-232. DOI: 10.1016/j.foodchem.2015.10.107

Eskilsson, C. S., and Bjorklund, E. (2000). “Analytical-scale microwave-assisted extraction,” J. Chromatogr. A 902, 227-250. DOI: 0.1016/s0021-9673(00)0092100923.

Farombi, E. O., Akanni, O. O., and Emerole, G. O. (2002). “Antioxidant and scavenging activities of flavonoid extract (kolaviron) of Garcinia kola seeds," Pharmaceutical Biology 40(2), 107-116. DOI: 10.1076/phbi.40.2.107.5838

Fu, X., Belwal, T., Cravotto, G., and Luo, Z. (2020). "Sono-physical and sono-chemical effects of ultrasound: Primary applications in extraction and freezing operations and influence on food components," Ultrasonics Sonochemistry 60, 1-23. DOI: 10.1016/j.ultsonch.2019.104726

Guo, Z., Jin, Q., Fan, G., Duan, Y., Qin, C., and Wen, M. (2001). "Microwave-assisted extraction of effective constituents from a Chinese herbal medicine Radix puerariae," Analytica Chimica Acta 436(1), 41-47. DOI:10.1016/S0003-2670(01)00900-X

Ji, Z., and Su, Y. (2006). "Effects of planting modes on secondary metabolite contents in Eucommia ulmoides barks," Acta Botanica Boreali-Occidentalia Sinica 26(9), 19111915.

Jing, C.-L., Huang, R.-H., Su, Y., Li, Y.-Q., and Zhang, C.-S. (2019). "Variation in chemical composition and biological activities of Flos Chrysanthemi indici essential oil under different extraction methods," Biomolecules 9(10), 1-13. DOI: 10.3390/ biom9100518

Memarzadeh, S. M., Gholami, A., Pirbalouti, A. G., and Masoum, S. (2020). "Bakhtiari savory (Satureja bachtiarica Bunge.) essential oil and its chemical profile, antioxidant activities, and leaf micromorphology under green and conventional extraction techniques," Industrial Crops and Production 154, 1-11. DOI: 10.1016/j. indcrop.2020.112719

Moreno, M. I. N., Isla, M. I., Sampietro, A. R., and Vattuone, M. A. (2000). “Comparison 
of the free radical-scavenging activity of propolis from several regions of Argentina," Journal of Ethnopharmacology 71(1-2), 109-114. DOI: 10.1016/s0378-

8741(99)00189-0

Nguyen, M. T. T., Awale, S., Tezuka, Y., Tran, Q. L., Watanabe, H., and Kadota, S. (2004). "Xanthine oxidase inhibitory activity of Vietnamese medicinal plants,"

Biological and Pharmaceutical Bulletin 27(9), 1414-1421. DOI:

10.1248/bpb.27.1414

Niu, X., Xu, D., Luo, J., and Kong, L. (2016). "Main iridoid glycosides and HPLC/DADQ-TOF-MS/MS profile of glycosides from the antioxidant extract of Eucommia ulmoides Oliver seeds," Industrial Crops and Products 79, 160-169. DOI:

10.1016/j.indcrop.2015.11.027

Orak, H. H., Yagar, H., and Isbilir, S. S. (2012). "Comparison of antioxidant activities of juice, peel, and seed of pomegranate (Punica granatum L.) and inter-relationships with total phenolic, tannin, anthocyanin, and flavonoid contents," Food Science and Biotechnology 21, 373-387. DOI: 10.1007/s10068-012-0049-6

Pan, Y., Niu, Y., Li, C., Zhai, Y., Zhang, R., Guo, X., and Mei, Q. (2014). "Du-zhong (Eucommia ulmoides) prevents disuse-induced osteoporosis in hind limb suspension rats," American Journal of Chinese Medicine 42(1), 143-155. DOI:

10.1142/S0192415X14500104

Wang, W., Yuan, T., Wang, K., Cui, B., and Dai, Y. (2012). "Combination of biological pretreatment with liquid hot water pretreatment to enhance enzymatic hydrolysis of Populus tomentosa," Bioresource Technology 107, 282-286. DOI:

10.1016/j.biortech.2011.12.116

Wang, Y.-F., Li, C.-S., Collinson, M. E., Lin, J., and Sun, Q.-G. (2003). “Eucommia (Eucommiaceae), a potential biothermometer for the reconstruction of paleoenvironments," American Journal of Botany 90(1), 1-7. DOI: 10.3732/ajb.90.1.1

Xu, H., Zhu, L., Dong, J., Wei, Q., and Lei, M. (2015). “Composition of Catalpa ovata seed oil and flavonoids in seed meal as well as their antioxidant activities," Journal of the American Oil Chemist's Society 92(3), 361-369. DOI: 10.1007/s11746-015-25956

Yan, R., Cao, Y., Chen, C., Dai, H., Yu, S., Wei, J., Li, H., and Yang, B. (2011). "Antioxidant flavonoids from the seed of Oroxylum indicum," Fitoterapia 82(6), 841848. DOI: 10.1016/j.fitote.2011.04.006

Yao, X., Deng, J., and Huang, H. (2012). "Genetic diversity in Eucommia ulmoides (Eucommiaceae), an endangered traditional Chinese medicinal plant," Conservation Genetics 13(6), 1499-1507. DOI: 10.1007/s10592-012-0393-3

Zhang, L., Ji, X., Tan, B., Liang, Y., Liang, N., Wang, X., and Dai, H. (2010). "Identification of the composition of fatty acids in Eucommia ulmoides seed oil by fraction chain length and mass spectrometry," Food Chemistry 121(3), 815-819. DOI: 10.1016/j.foodchem.2009.12.089

Zhu, S., Li, J., Liu, Y. and Chen, L. (2020). "Formation and stability of Eucommia ulmoides Oliver seed oil-loaded inverse microemulsion formed by food-grade ingredients and its antioxidant activities," Journal of Food Science 85(5), 1489-1499. DOI: $10.1111 / 1750-3841.15103$

Article submitted: June 29, 2021; Peer review completed: September 5, 2021; Revised version received and accepted: September 13, 2021; Published: September 17, 2021. DOI: 10.15376/biores.16.4.7367-7378 